www.jmscr.igmpublication.org Impact Factor 5.84

Index Copernicus Value: 83.27

ISSN (e)-2347-176x ISSN (p) 2455-0450

crossref DOI: _https://dx.doi.org/10.18535/jmscr/v5i4.222

Journal Of Medical Science And Clinical Research

\title{
Abnormal Platelets Indices is Significant Hematological Parameters as a Prognostic \& Recovery Tool of Plasmodium Vivex Malaria for Acute Disease with Illness
}

\author{
Author \\ Dr Akshay Surana (MD Pathology) \\ Email:asurana06@yahoo.com
}

\begin{abstract}
Aims \& Objectives: Reduced the morbidity and mortality of malaria due to plasmodium vivex Reduced the incidence of plasmodium vivex induced acute illness and prevent the complication.

Material \& Methods: Blood was collected in a sterile EDTA containing tube and processed following our established laboratory protocol .A complete blood counting including $\mathrm{HB} \%, \mathrm{PCV}$, Red cell indices, platelet count with platelets indices MPV and total white cell count and differential was done by Automated blood cell counter and peripheral blood smear examination by thin film and thick film. The all cell count indices including RBC, WBC count with differential along with platelets count was further confirmed by manual oil immersion smear study method. Peripheral smears study was done with field A and B stain and leishman stain.

Conclusion: Thrombocytopenia is one of the most common complications of the P. vivax malaria and as a prognostic indicator of acute illness of malaria. Thrombocytopenia with raised Mean platelets volume hematological parameter is a adequate prognostic \& diagnostic tool for acute illness and parasitimic index Keyword: Mean platelets volume Thrombocytopenia Platelets aggregation.
\end{abstract}

\section{Material \& Methods}

Study area and design- The present study was conducted at the Department of medicine and pathology cure well hospital pvt.ltd and associated referral hospital Indore M.P. The study was designed as a observational retrograde with prospective hospital based study over a period of time from 2016 to 2017 years

Ethical consideration- Blood was collected in a sterile EDTA containing tube and processed following our established laboratory protocol then generate the report of each patient. Take informed consent was obtained from all study participant. Start proper management as a guide line.
Patient's selection criteria- The study target those patients who's present with complain of fever with chills rigger. blood sample pathology report shows plasmodium malaria positive We include both OPD and IPD patients with all age groups ,male and female both gender for study. Sample size is 70 patients.

Complete Blood Count (Cbc) And Peripheral Smear.

Materials

1. Purple vacutainer tube or capillary collector (EDTA) ethylenediaminetetraacetate

2. Slides and blue capillary tube 
3. Needle or lancet

4. Vacutainer holder

5. Alcohol swab

6. Cotton balls

7. Absorbent materials

8. Slide case

\section{Procedure}

1. Specimen is collected into EDTA (purple) vacutainer. (5 or $7 \mathrm{ml}$ volume)

Preparation of peripheral blood smear from prolong stored > 6hr) sterile EDTA containing blood sample tube at room temperature .

Step 1. A small drop of venous blood is placed on a glass microscope slide, using a glass capillary pipette.

Step 2. A spreader slide is positioned at $45^{\circ}$ angle and slowly drawn toward the drop of blood.

Step 3. The spreader slide is brought in contact with the drop of blood and is being drawn away.
Step 4. The spreader slide is further pulled out, leaving a thin layer of blood behind.

Step 5. The blood smear is nearly complete.

Step 6. End result will be a glass slide with a wellformed blood film. After drying for about 10 minutes, the slide is fixed in methanol \& stained with field $\mathrm{A}$ and $\mathrm{B}$ stain.

A well-made peripheral smear is thick at the frosted end and becomes progressively thinner toward the opposite end. The "zone of morphology" (area of optimal thickness for light microscopic examination) should be at least $2 \mathrm{~cm}$ in length. The smear should occupy the central area of the slide and be margin-free at the edges.

\section{Hematological examination-}

Hematological examination including $\mathrm{HB} \%, \mathrm{PCV}$, Red cell indices, platelet count and total white cell count with differential count should be done on peripheral smears stained with field $\mathrm{A}$ and $\mathrm{B}$ stains.

\section{Observation \& Discussion}

\begin{tabular}{|l|c|c|c|}
\hline \multirow{2}{*}{ Plasmodium Vivex } & \multirow{2}{*}{ Type of severity } & \multicolumn{2}{|c|}{ Total Cases (n=70) } \\
\cline { 3 - 4 } & & No. & $\%$ \\
\hline Thrombocytopenia & Acute illness & 48 & $64.00 \%$ \\
\hline Non Thrombocytopenia & Non acute illness & 22 & $36.00 \%$ \\
\hline \multicolumn{3}{|c|}{} \\
\hline \multirow{2}{*}{ Plasmodium Vivex } & \multirow{2}{*}{ Type of severity } & Notal Cases (n=70) \\
\cline { 3 - 4 } & & 24 & $38.66 \%$ \\
\hline MPV within normal limit & Non acute illness & 46 & $61.33 \%$ \\
\hline Raised MPV & Acute illness & & \\
\hline
\end{tabular}

\begin{tabular}{|c|c|c|c|}
\hline \multirow{2}{*}{ Plasmodium Vivex } & \multirow{2}{*}{ Type of severity } & \multicolumn{2}{|c|}{ Total Cases $(n=70)$} \\
\hline & & No. & $\%$ \\
\hline P-LCR within normal limit & Non acute illness & 26 & $38.66 \%$ \\
\hline Raised P-LCR & Acute illness & 44 & $61.33 \%$ \\
\hline
\end{tabular}

\begin{tabular}{|l|c|c|c|}
\hline \multirow{2}{*}{ Plasmodium Falciparum } & \multirow{2}{*}{ Type of severity } & \multicolumn{2}{|c|}{ Total Cases $(\mathrm{n}=50)$} \\
\cline { 3 - 4 } & & No. & $\%$ \\
\hline Thrombocytopenia & Non Acute illness & 10 & $22.00 \%$ \\
\hline Non Thrombocytopenia & Acute illness ( Cerebral ) & 40 & $78.00 \%$ \\
\hline
\end{tabular}

\begin{tabular}{|c|c|c|c|}
\hline \multirow{2}{*}{ Plasmodium Falciparum } & \multirow{2}{*}{ Type of severity } & \multicolumn{2}{|c|}{ Total Cases (n=50) } \\
\cline { 3 - 4 } & & No. & $\%$ \\
\hline MPV with normal limit & acute illness & 36 & $74.00 \%$ \\
\hline Raised MPV & Non acute illness & 14 & $26.00 \%$ \\
\hline \multirow{2}{*}{ Plasmodium Falciparum } & \multirow{2}{*}{ Type of severity } & \multicolumn{2}{|c|}{ Total Cases $(\mathrm{n}=50)$} \\
\cline { 3 - 4 } & Non acute illness & 20 & $38.66 \%$ \\
\hline P-LCR within normal limit & Acute illness & 40 & $61.33 \%$ \\
\hline Raised P-LCR & &
\end{tabular}


Data analysis in following hematological parameters with the difference under the Extended Mantel-Haenszel test for trend of chi -Squares test. Chi-sq. test X2 Value $=0.873[\mathrm{DF}=1] 2$ sided $\mathrm{P}=0.350$ For trend in a given direction: $\mathrm{P}$ $=0.175$

\section{Conclusion}

P. vivax mono infection presented with thrombocytopenia and raised MPV suggesting that acute illness (Alexandre et al. 2010) (Santana Filho et al. 2007, Tjitra et al. 2008) .(Patel et al. 2004). . vivax malaria has now clearly emerged as a potentially lethal condition $\underline{11} \underline{2 l}$, despite of having previously been considered a benign disease. $\mathrm{P}$. vivax is more widely distributed than $P$. falciparum and has potential to cause morbidity and mortality. ${ }^{[3] .[4]}$, Kochar and colleagues have recently shown that severe thrombocytopenia (platelet count $<20 \times 10^{3} / \mathrm{mm}^{3}$ ) is a common manifestation in patients with vivax monoinfection confirmed by PCR ${ }^{[5], 66]}$. Thrombocytopenia in malaria seems to be a multifactorial phenomenon and probably involves an increase in platelets destruction and consumption $[7] \cdot[8]-[10]$.

$P$. $\quad$ ivax revealed a high frequency of thrombocytopaenia and raised MPV The high frequency of warning signs of severe malaria cases can be explained by the fact that this study was conducted in a reference hospital for malaria diagnosis and treatment. to that reported by Franklin et al. ${ }^{[11]}$ and Coelho et al. ${ }^{[12]}$ regarding patients infected with $P$. vivax in the Amazon region. Increased MPV in malaria has been observed in other studies maskar as acute illness. ${ }^{[13,14]}$.

It is well known that non-immune individuals are more susceptible to developing severe malaria. Furthermore, the delay of onset of malaria treatment is directly associated with severe disease outcomes ${ }^{[15]}$. Raised MPV predominated in the patients with any indicator of severe malaria caused by $P$. vivax, such as primo infection, longer symptom duration, and the presence of clinical signs and laboratory indicators of severe malaria. Larger platelets are metabolically and enzymatically more active and have a more important role in the inflammatory process ${ }^{[16]}$. Elevated MPV has also been described in patients with severe sepsis and is explained by the quick splenic and medullary release of large volumes of platelets in response to the increased demand for these cells ${ }^{[17]}$. In fact, studies in humans and rats showed that large platelets are functionally more active and have a lower threshold for aggregation and the release of their activity ${ }^{[9,16]}$. It is well known that PDW is linearly correlated with MPV in normal individuals.

\section{References}

1. J. Lou, Y. R. A. Donati, P. Juillard et al., "Platelets play an important role in TNFinduced microvascular endothelial cell pathology," The American Journal of Pathology, vol. 151, no. 5, pp. 1397-1405, 1997.

2. S. C. Wassmer, C. Lépolard, B. Traoré, B. Pouvelle, J. Gysin, and G. E. Grau, "Platelets reorient Plasmodium falciparum-infected erythrocyte cytoadhesion to activated endothelial cells," Journal of Infectious Diseases, vol. 189, no. 2, pp. 180-189, 2004.

3. S. C. Wassmer, J. B. De Souza, C. Frère, F. J. Candal, I. Juhan-Vague, and G. E. Grau, "TGF- $\beta 1$ released from activated platelets can induce TNF-stimulated human brain endothelium apoptosis: a new mechanism for microvascular lesion during cerebral malaria," Journal of Immunology, vol. 176, no. 2, pp. 11801184, 2006.

4. B. O. Carvalho, S. C. P. Lopes, P. A. Nogueira et al., "On the cytoadhesion of Plasmodium vivax-infected erythrocytes," Journal of Infectious Diseases, vol. 202, no. 4, pp. 638-647, 2010.

5. A. J. Rodríguez-Morales, E. Sánchez, M. Vargas, et al., "Anemia and thrombocytopenia in children with Plasmodium vivax malaria," Journal of Tropical Pediatrics, vol. 52, pp. 49-51, 2005. 
6. P. J. Beale, J. D. Cormack, and T. B. Oldrey, "Thrombocytopenia in malaria with immunoglobulin (IgM) changes," British Medical Journal, vol. 1, no. 796, pp. 345-349, 1972.

7. WHO, "Severe falciparum malaria," Transactions of the Royal Society of Tropical Medicine and Hygiene, vol. 94, Supplement 1, pp. S1-S90, 2000.

8. M. V. G. Lacerda, Clinical manifestations and pathogenesis of malarial thrombocytopenia [Ph.D. thesis], Tropical Medicine Department, University of Brasília, 2007.

9. S. B. R. Silva, Evaluation of frequency and factors associated to thrombocytopenia caused by Plasmodium vivax [Master dissertation], Federal University of Mato Grosso, 2009.

10. P. Grynberg, C. J. Fernandes Fontes, and É. Martins Braga, "Association between particular polymorphic residues on apical membrane antigen 1 (AMA-1) and platelet levels in patients with vivax malaria," Clinical Microbiology and Infection, vol. 13, no. 11, pp. 1089-1094, 2007.

11. Franklin BS, Vitorino BLF, Coelho HC, Menezes-Neto A, Santos MLS, Campos FMF, Brito CF, Fontes CJ, Lacerda MV, Carvalho LH: Plasma circulating nucleic acids levels increase according to the morbidity of Plasmodium vivax malaria. PLoSOne 2011, 6:e19842.

12. Coelho HCC, Lopes SCP, Pimentel JPD, Nogueira PA, Costa FTM, Siqueira AM, Melo GC, Monteiro WM, Malheiro A, Lacerda MVG: Thrombocytopenia in Plasmodium vivaxmalaria is related to platelets phagocytosis.PLoS One 2013, 8:e63410.

13. Maina RN, Walsh D, Gaddy C, Hongo G, Waitumbi J, Otieno L, Jones D, Ogutu BR: Impact of Plasmodium falciparum infection on haematological parameters in children living in western Kenya.Malar $\mathbf{J}$ 2010, 9(Suppl 3)

14. Ladhani S, Lowe B, Cole AO, Kowuondo K, Newton CRJC: Changes in white blood cells and platelets in children with falciparum malaria: relationship to disease outcome. Br J Haematol 2002, 119:839847.

15. WHO: Guidelines for the treatment of malaria. 2nd edition. Geneva: World Health Organization; 2010.

16. Thon JN, Italiano JE: Does size matter in platelet production 2012, 120:1552-1561

17. Becchi C, Al Malyan M, Fabbri LP, Marsili M, Boddi V, Boncinelli S: Mean platelet volume trend in sepsis: is it a useful parameter Minerva Anestesiol 2006, 72:749-756. 